\title{
Association mapping for cold tolerance in two large maize inbred panels
}

\author{
Pedro Revilla ${ }^{1 *}$, Víctor Manuel Rodríguez ${ }^{1}$, Amando Ordás ${ }^{1}$, Renaud Rincent ${ }^{2}$, Alain Charcosset $^{2}$, \\ Catherine Giauffret ${ }^{3}$, Albrecht E. Melchinger ${ }^{4}$, Chris-Carolin Schön ${ }^{5}$, Eva Bauer ${ }^{5}$, Thomas Altmann ${ }^{6}$, \\ Dominique Brunel ${ }^{7}$, Jesús Moreno-González ${ }^{8}$, Laura Campo ${ }^{8}$, Milena Ouzunova ${ }^{9}$, Ángel Álvarez ${ }^{10}$, \\ José Ignacio Ruíz de Galarreta ${ }^{11}$, Jacques Laborde ${ }^{12}$ and Rosa Ana Malvar ${ }^{1}$
}

\begin{abstract}
Background: Breeding for cold tolerance in maize promises to allow increasing growth area and production in temperate zones. The objective of this research was to conduct genome-wide association analyses (GWAS) in temperate maize inbred lines and to find strategies for pyramiding genes for cold tolerance. Two panels of 306 dent and 292 European flint maize inbred lines were evaluated per se and in testcrosses under cold and control conditions in a growth chamber. We recorded indirect measures for cold tolerance as the traits number of days from sowing to emergence, relative leaf chlorophyll content or quantum efficiency of photosystem II. Association mapping for identifying genes associated to cold tolerance in both panels was based on genotyping with 49,585 genome-wide single nucleotide polymorphism (SNP) markers.

Results: We found 275 significant associations, most of them in the inbreds evaluated per se, in the flint panel, and under control conditions. A few candidate genes coincided between the current research and previous reports. A total of 47 flint inbreds harbored the favorable alleles for six significant quantitative trait loci (QTL) detected for inbreds per se evaluated under cold conditions, four of them had also the favorable alleles for the main QTL detected from the testcrosses. Only four dent inbreds (EZ47, F924, NK807 and PHJ40) harbored the favorable alleles for three main QTL detected from the evaluation of the dent inbreds per se under cold conditions. There were more QTL in the flint panel and most of the QTL were associated with days to emergence and DPSII.
\end{abstract}

Conclusions: These results open new possibilities to genetically improve cold tolerance either with genome-wide selection or with marker assisted selection.

Keywords: GWAS, Maize, Cold tolerance, Chilling, QTL

\section{Background}

Maize (Zea mays L.) is a tropical crop currently cultivated in high latitudes thanks to historical improvements of cold tolerance, reductions in growth cycle, and adaptation to long days [1]. Improved cold tolerance would allow earlier sowing dates and thus would enable escaping summer drought, pests and diseases [2]. Earlier sowing would also lead to longer vegetation periods, which can be used for biomass accumulation. Maize genotypes grown in temperate areas have moderate cold tolerance

\footnotetext{
*Correspondence: previlla@mbg.csic.es

${ }^{1}$ Misión Biológica de Galicia, Spanish National Research Council (CSIC), PO

Box 2836080, Pontevedra, Spain

Full list of author information is available at the end of the article
}

and previous studies have found only some genotypes with partial tolerance [3-6].

Since the advent of molecular markers and QTL studies, several reports have been published with limited impact on maize breeding for cold tolerance [7]. QTL reported for cold tolerance were associated with traits such as chlorophyll content or photosynthesis [5, 8-10]. Strigens et al. [11] carried out genome-wide association mapping for cold tolerance in a collection of maize inbred lines and obtained 19 QTL explaining between 5.7 and $52.5 \%$ of the phenotypic variance for early growth and chlorophyll fluorescence. Due to the highly complex architecture of cold tolerance-traits, they proposed whole genome prediction approaches 
rather than classical marker assisted selection for improving chilling tolerance of maize.

Maize grown in cold areas of Europe is reported to stand low temperatures better than maize from other origins. Moreover, genotypes belonging to the European Flint germplasm showed better cold tolerance than those originating from the Corn Belt Dent [11, 12]. Previous reports found sources of cold tolerance in diverse collections of European germplasm [4, 6, 13-17]. The largest study for evaluation of cold tolerance was reported by Revilla et al. [4] who evaluated the same two large panels of maize inbred lines adapted to Europe for cold tolerance that was used for the present study. These authors found that the dent and flint germplasm most tolerant to cold temperatures were the Northern Flint D171 and the Iodent PH207 groups, respectively. They also concluded that models intending the prediction of final performance from traits scored in early developmental stages are not precise enough for breeding. Nevertheless, breeding for cold tolerance could be accomplished by combining inbreds from groups that can provide sources of favorable alleles for cold tolerance. The evaluation method and the traits used for assessing cold tolerance at early stages of development have been defined according to our previous experience [4] taking into account traits that estimate cold tolerance for the subsequent steps of the heterotrophic stage from germination to endosperm depletion. According to previous information [3], the main detrimental effects of cold conditions at early stages of maize development are delayed emergence, reduced chlorophyll content and efficiency of photosystem II, and decreased early vigor and biomass synthesis. Therefore, we have recorded data related to those features that can accurately be measured with large numbers of genotypes.

The objective of this study was to carry out genome wide association analyses for cold tolerance in two large panels of maize inbred lines and to suggest possible strategies for breeding new genotypes with improved cold tolerance.

\section{Methods}

\section{Plant material}

Two panels of 306 dent and 292 flint maize inbred lines $[4,18]$ representing the breeding germplasm adapted to European agro-climatic conditions were evaluated per se and as testcrosses [4]. The panels were built from the collections of Spanish, French, and German breeders involved in this research. They come from Western Europe and the USA. The inbreds are public and have been released throughout the history of maize breeding. The seed used in this study was produced by the INRA (France), the Technical University of Munich (Germany) and the Spanish institutions CSIC, NEIKER and CIAM.
The dent inbreds were crossed to the flint tester UH007 and the flint inbreds to the dent tester F353 in a winter nursery in 2010 in order to evaluate testcross performance using each tester as the male parent and the inbreds of the panels as female parents [4].

\section{Growth chamber trials}

We used a cold chamber of $20 \mathrm{~m}^{3}$ built inside a laboratory with modulated panels, isolated with injected polyurethane. The 598 flint and dent inbreds were evaluated per se, along with six checks (C105, CO109, D152, EA1027, F816, FP1). Dent and flint panels were evaluated separately in adjacent trials under cold and control conditions. After inbreds per se evaluation, testcrosses were evaluated for cold and for control conditions. Evaluations of inbreds per se and testcrosses in control and cold conditions were made in consecutive runs. Each trial followed a randomized complete block design with six replications [4].

Maize kernels were planted in a multi-pot trays; using one cell for each kernel. Each cell had a surface of $3 \mathrm{~cm} \times$ $2.5 \mathrm{~cm}$ and $5 \mathrm{~cm}$ depth filled with sterilized peat (Gramoflor GmbH \& Co. KG, Vechta, Germany). Six plants per inbred or testcross were used in each run of the growth chamber as there were six repetitions with one plant per replication in each trial. The experiments were watered after planting; afterwards the trials were watered as needed. Temperature and light conditions for the cold experiments were $14{ }^{\circ} \mathrm{C} / 14 \mathrm{~h}$ with light and $8{ }^{\circ} \mathrm{C} / 10 \mathrm{~h}$ in the dark. In the control experiments, plants were grown at $25{ }^{\circ} \mathrm{C} / 14 \mathrm{~h}$ light and $20{ }^{\circ} \mathrm{C} / 10 \mathrm{~h}$ dark. Cool light was provided by seven very high output fluorescent lamps per shelf with a photosynthetic photon flux of $228 \mu \mathrm{mol} \mathrm{m} \mathrm{m}^{-2} \mathrm{~s}^{-1}$. Distance between shelves and fluorescent lamps was $0.5 \mathrm{~m}$.

In every trial, data were recorded for 1) number of days from sowing to emergence, 2) relative leaf chlorophyll content (SPAD units) in the second leaf, using a hand-held CCM-200 Chlorophyll Content Meter (OptiSciences, Tyngsboro, Massachusetts, USA), 3) quantum efficiency of photosystem II (ФPSII) recorded in the second leaf by using a portable OS-30p Chlorophyll Fluorometer (Opti-Sciences, Tyngsboro, Massachusetts, USA) [4]. For inbreds per se we scored early vigor using a visual scale from $1=$ weak plants to $9=$ vigorous plants. For testcrosses, dry weight was determined by weighing the plants after drying them in an oven at $80{ }^{\circ} \mathrm{C}$ during 5 days.

\section{Statistical analysis}

All inbreds were genotyped with the Illumina MaizeSNP50 BeadChip that includes 49,585 SNPs covering all 10 maize chromosomes [19]. According to these authors, the design of this library started with 839,350 SNP 
derived from the first generation haplotype map (Panzea set.), a collection of markers arising between B73 and Mo17 provided by Syngenta, and SNPs chosen from comparative sequencing of $\mathrm{B} 73$ and $\mathrm{F} 2$, provided by INRA, as well as SNPs collected from various other published marker sets [19]. They eliminated duplicated SNPs and those SNPs that contained nearby known SNPs in both flanking sequences, followed by four further stages of selection aiming at optimizing coverage of the genome and even spacing throughout the genome. Data were filtered to exclude SNPs with more than $20 \%$ missing values and less than $5 \%$ minor allele frequency. Heterozygote genotype calls were considered as missing data. 42,214 and 35,963 SNPs in the -Dent and Flint panels, respectively were used for GWAS. Genotypic data are available at Rincent et al. [18].

We used the genotyping matrix and a genetic kinship matrix (K) described earlier by Rincent et al. [18]. Best linear unbiased estimators (BLUEs) for inbred lines and testcrosses were calculated for each panel with the SAS mixed model procedure (PROC MIXED) in SAS software version 9.3 [20] considering inbred lines or testcrosses as fixed effects and replications as random effects.

Genome-wide association analysis based on mixed linear model (MLM) was performed with software Tassel 4.1.26 [21]. The MLM used by Tassel was

$$
\mathbf{y}=\mathbf{X} \boldsymbol{\beta}+\mathbf{Z u}+\mathbf{e}
$$

where $\mathbf{y}$ is the vector of phenotypes (BLUEs), $\boldsymbol{\beta}$ is a vector of fixed effects, including the SNP marker tested, $\mathbf{u}$ is a vector of random additive effects (inbred lines), $\mathbf{X}$ and $\mathbf{Z}$ represent matrices of $1 \mathrm{~s}$ and $0 \mathrm{~s}$ related to $\boldsymbol{\beta}$ and $\mathbf{u}$ respectively, and $\mathbf{e}$ is a vector of random residuals. The variance of random line effects was modeled as $V a r$ $(u)=K \sigma_{a}^{2}$, where $\mathbf{K}$ is the $n \times n$ matrix of pairwise kinship coefficients and $\sigma_{a}^{2}$ is the estimated additive genetic variance [22]. Restricted maximum likelihood estimates of variance components were obtained by using the optimum compression level (compressed MLM) and population parameters previously determined (P3D) options in Tassel [23]. The optimum compression level option reduces the computation demand by clustering the $(n)$ total individuals into $(s)$ groups based on their realized genomic relationships, allowing the original $\mathbf{K}$ matrix to be replaced by a smaller relationship matrix.

The statistical significance threshold was set to $0.05 /$ $\mathrm{M}_{\mathrm{eff}}$, which corresponds to a Bonferroni correction on $M_{\text {eff }}$ tests, $M_{\text {eff }}$ being the number of independent tests estimated [24]. We used the same threshold as Rincent et al. [18] because they used the same sets of lines. They evaluated 3638 and 3527 independent tests in the Dent and Flint panels respectively, which led to a $-\log _{10}$
(P-value) threshold of 4.9 in both panels. Significant SNPs separated by less than $700 \mathrm{~kb}$ were considered as a single QTL for the interpretation of the results. Likewise, if SNP1 was linked to SNP2, and SNP 2 was linked to SNP 3, then we considered SNPs 1, 2 and 3 the same QTL although SNP 1 and SNP 3 differed by $700 \mathrm{~kb}$. We examined a $700 \mathrm{~kb}$ region left and right of each significant SNP in order to identify candidate genes of interest by use of the MaizeGDB genome browser [25].

Local linkage disequilibrium (LD)(r2) among markers in an $1500 \mathrm{~kb}$ interval surrounding the significant SNPs and common haplotype patterns were assessed in Haploview version 4.2 [26]. Haplotype blocks were defined with the confidence interval method of Gabriel et al. [27]. Only SNPs with a MAF $\geq 0.05$ and less than 0.20 missing data were used to estimate LD.

Heritability $\left(\hat{h}^{2}\right)$ for each panel (dent, flint), each condition (cold and control) and inbreeding level (inbreed, hybrid) were estimated for each trait on a family-mean basis as described by Holland et al. [28].

\section{Results and discussion \\ Association analyses}

The compressed mixed linear model analyses for cold tolerance traits reduced the genetic effects by a compression level from 1 to 18.6 , being lowest for early vigor/early dry weight followed by days to emergence, and highest for ФPSII followed by chlorophyll content, although in most cases compression levels were in the range 1 to 2 (Additional file 1: Table S1). Compression levels were made for grouping inbred lines and for making the subsequent analyses with groups, taking into account the similarities among inbreds within the panels. Random genetic variability was not uniformly distributed for diverse traits and evaluation conditions and the number of individuals per group was variable as well, indicating that residual random variability was inconsistently distributed within groups.

According to Zhang et al. [23] the best control of the false positive rate for the validation of the compressed mixed linear model approach was when the compression levels were within a range of 1.5 to 10 [28]. Therefore, the control of false positives by our model is efficient for days to emergence and also for early vigor/early dry weight. Focusing on inbreds per se under control conditions, we should note that compression level was less than 1.5 for all traits except days to emergence for flint panel and early vigor for dent panel. Background genetic effects modeled by $\mathrm{K}$ ranged from $2 \%$ of the total phenotypic variation to $79 \%$ in lines and from 4 to $59 \%$ in hybrids. The proportion was higher for flint than for dent panel, for inbreds per se than for hybrids, and for ФPSII and early vigor. Finally, the proportion was 
similar for evaluations under cold and control conditions, (Additional file 1: Table S1).

In general, traits showed intermediate heritability values $\left(h^{2}\right.$ around 0.50) except for days to emergence. For this trait, low heritability value was obtained $\left(h^{2}\right.$ around 0.25 , Additional file 1: Table S1). For ФPSII, inbreeds showed higher heritability values than hybrids. Heritability values were similar for dent and flint panels and for control and cold conditions. We expect higher genetic variability under cold conditions and higher error variance therefore heritability was similar under both evaluation conditions.

\section{QTL analyses}

The numbers of markers adequate for GWAS analysis depends of the rate of linkage disequilibrium (LD) decay, the panel diversity, and the objective of GWAS analysis. LD decays fast and the diversity is large in maize, so a high number of markers should be used especially if the approaches is looking for candidate genes. However, both panels (dent and flint) are composed of lines adapted to Europe and therefore we expect less variability than in the American panel where there are tropical and temperate lines. Besides, the objective is looking for QTL associated to cold tolerance traits to explore new breeding possibilities rather than looking genes related to cold tolerance. Therefore, for these panels the Illumina MaizeSNP50 BeadChip is adequate [29].

QTL analyses were made separately for each panel (dent and flint), inbreeding level (inbreds per se and testcrosses) and environmental conditions (cold and control), although we focused mainly on the analyses of inbreds per se under cold conditions (see below). Number of panel lines used for GWAS is highly important for the mapping power. For traits regulated by large number of loci with small effect increasing sample size will improve power. However, it will often increase genetic heterogeneity and could reduce the detection power especially for traits that are important for adaptation like cold tolerance traits [30]. Besides, it is important to notice that most European flint inbreds have some historical and genetic relationships and most of them come from germplasm that has been adapted to European conditions for several centuries. Conversely, the dent panel includes genotypes that have been introduced in Europe during the last decades without consistent historical or genetic relationships among groups [4]. Therefore, flints and dents should be analyzed separately in order to respect the genetic structure of the genotypes.

Altogether, we found 275 SNPs significantly associated to any trait, most of them were found for the inbreds evaluated per se (164 significant associations/71 QTL) (Fig. 1). The higher number of significant QTL found in inbred lines, compared to testcrosses could be due to the masking effect of the inbred tester used for

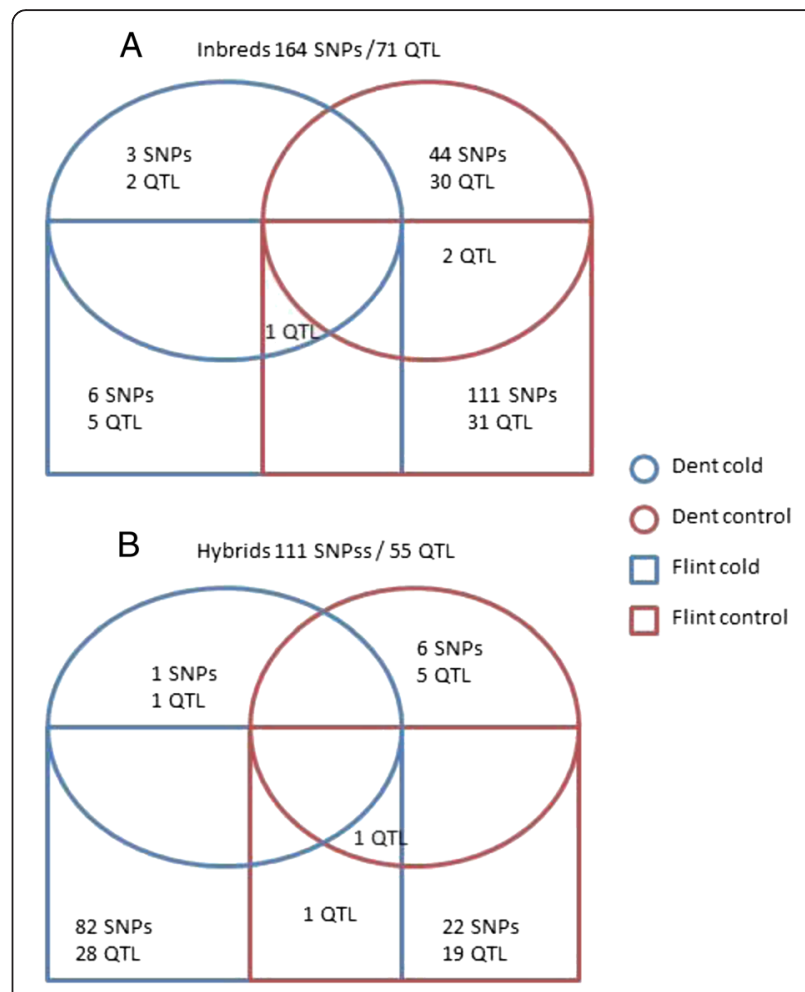

Fig. 1 Significant SNPS and QTL associated to cold tolerance traits in two association panels of maize. Inbred lines were evaluated per se (a) and in testcrosses (b) under control and cold conditions

producing testcrosses, as pointed out by previous reports [4]. Most of the significant associations (117) were found in the flint panel, probably because there was more variability for traits related to early plant development among flint inbred lines than among dent lines [4]. Finally, most QTL (90) were identified under control conditions (38 in cold conditions), presumably because experimental errors were higher under stress conditions than under optimum conditions [3]. Similarly, Strigens et al. [11] found more QTL under control conditions than under cold conditions. However, Strigens et al. [11] found only 19 QTL under cold conditions probably because they evaluated a panel with fewer lines (375 dent and flint inbred lines) than our two panels together (306 dent and 292 flint inbred lines).

Evaluations of dent testcrosses under cold conditions identified one QTL for days to emergence on chromosome 3 (chr3) and five QTL under control conditions on chr4, 5, 7 and 10 (Fig. 1, Additional file 2: Table S2). For ФPSII, dent testcrosses yielded only one QTL on chr10 under control conditions and none under cold conditions. Flint testcrosses evaluated under cold conditions had 29 QTL for days to emergence located on all chromosomes except chr5, while under control conditions there were 20 QTL on all chromosomes. For ФPSII, flint 
testcrosses had one QTL on chr4 under cold conditions, and none under control conditions. For early dry weight there was only one QTL on chr9 for flint testcrosses under control conditions.

Evaluations of dent inbreds per se under control conditions identified 21 SNPs (16 QTLs) on chr1, 2, 3, 5, 7, 8 , and 10 for days to emergence, and for DPSII there were 23 SNPs (18 QTL) on chr1, 2, 3, 5, 7, 9, and 10. Six significant SNPs were found in both traits (Additional file 2: Table S2). Flint inbreds evaluated per se under control conditions revealed 11 SNPs (8 QTL) for days to emergence on chr6, 7, 8, 9, and 10, and 100 SNPs (26 QTL) on chr3, 4, 5, 9, and 10 for ФPSII.

Nine SNPs (8 QTL) were significantly associated to cold tolerance-related traits for the inbred lines evaluated per se under cold conditions, three of them for the dent panel and six for the flint panel (Table 1). The traits with significant SNPs were early vigor (4 SNPs), three of them for the Flint panel (Fig. 2), days to emergence (1), ФPSII (2) and SPAD (2) that were located on chr1, 3, 4, 5 and 7 . The additive effect indicates that the major allele provides increased cold tolerance for the QTL of days to emergence, both QTL of ФPSII and one QTL of early vigor and less cold tolerance for both QTL of SPAD and three QTL of early vigor. The frequency of the alleles at each QTL was moderate except for some cases such as PZE-101084685 with a frequency ratio of $27 / 213$. Finally, these QTL explained a proportion of phenotypic variance between 8 and $14 \%$, a range similar to that reported in previous publications of QTL for cold tolerance [11].
For significant SNPs under cold conditions, an analysis of variance was performed to test SNP $\times$ environment interaction. SNPs detected in the dent panel did not show significant interactions with environment. On the other hand, the interactions were significant for five of six significant SNPs detected in the Flint panel. However, the interactions are range type because 1) SNP alleles did not differ under control conditions, or 2) the favorable allele is the same under both conditions but the difference between the two alleles is significantly higher under cold conditions (data not shown). This shows again the different behavior of Flint and Dent panels under cold conditions.

Local LD in a $1400 \mathrm{~kb}$ interval surrounding the significant SNPs shows the rapid decay of LD between pairs of markers [31]. In fact, 3 of 9 significant SNPs cannot be included in haplotype blocks defined with the confidence interval method [31] (Fig. 3). Composition haplotype groups vary from 1 to 8 SNPs. For days to emergence haplotypes with favorable alleles are found in $80 \%$ of the lines while for chlorophyll content (SNP PZE101159230) haplotype with all favorable alleles are only in $20 \%$ of genotypes. Haplotype with all favorable alleles for early vigor is found in a frequency of less than $10 \%$ for both SNPs PZE-101106625 and PZE-107098206 (Table 2)

Candidate genes were chosen based on the genomic sequence of the maize inbred line B73 [32] within an interval of $100 \mathrm{kbp}$ wide flanking regions upstream and downstream from the significant SNP. We identified the closest candidate gene for the QTL in flint associated to

Table 1 SNPs significantly associated to early growth-related traits, from association analyses in two panels of maize

\begin{tabular}{|c|c|c|c|c|c|c|c|c|}
\hline Inbred panel & Chromosome & Position & SNP & $P$-value & SNP alleles & Additive $^{a}$ effect & $\mathrm{N}^{\mathrm{b}}$ & $R^{2 c}$ \\
\hline \multicolumn{9}{|c|}{ Days to emergence } \\
\hline Flint & 3 & 145737736 & PUT-163a-78121249-4393 & $3.3 \times 10^{-6}$ & $\mathrm{~T} / \mathrm{C}$ & 0.67 & $201 / 40$ & 0.11 \\
\hline \multicolumn{9}{|c|}{ Chlorophyll content (SPAD) } \\
\hline Dent & 1 & 201477347 & PZE-101159230 & $1.4 \times 10^{-5}$ & $\mathrm{C} / \mathrm{T}$ & 0.34 & $234 / 57$ & 0.08 \\
\hline Dent & 4 & 172689894 & SYN2344 & $1.5 \times 10^{-5}$ & $A / G$ & 0.18 & 157/131 & 0.08 \\
\hline \multicolumn{9}{|l|}{${ }{ }^{P S} \|^{d}$} \\
\hline Flint & 1 & 73380804 & PZE-101084685 & $8.1 \times 10^{-6}$ & $\mathrm{~A} / \mathrm{C}$ & 59.5 & $27 / 213$ & 0.10 \\
\hline Flint & 4 & 20738948 & SYN24026 & $8.0 \times 10^{-6}$ & T/G & 56.6 & $38 / 203$ & 0.09 \\
\hline \multicolumn{9}{|l|}{ Early vigore } \\
\hline Dent & 1 & 110914351 & PZE-101106625 & $1.2 \times 10^{-5}$ & $C / T$ & 0.05 & 231/62 & 0.08 \\
\hline Flint & 5 & 27247368 & PZE-105041198 & $8.3 \times 10^{-6}$ & $\mathrm{C} / \mathrm{T}$ & 0.21 & $62 / 179$ & 0.11 \\
\hline Flint & 5 & 27857856 & PZE-105041551 & $3.4 \times 10^{-6}$ & $C / T$ & 0.21 & $123 / 97$ & 0.14 \\
\hline Flint & 7 & 153421340 & PZE-107098206 & $2.4 \times 10^{-6}$ & $\mathrm{C} / \mathrm{T}$ & 0.21 & $121 / 118$ & 0.10 \\
\hline
\end{tabular}

${ }^{a}$ The additive effect was calculated as half the difference between the mean of the homozygotes for the minor and the mean of the homozygotes for the major allele ${ }^{\mathrm{b}}$ Number of lines with each allele

${ }^{c} R^{2}$, proportion of total line mean variance explained by SNP as computed by Tassel software

dDPSII: Quantum efficiency of PSII

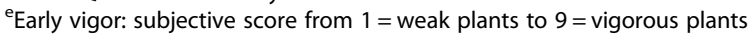




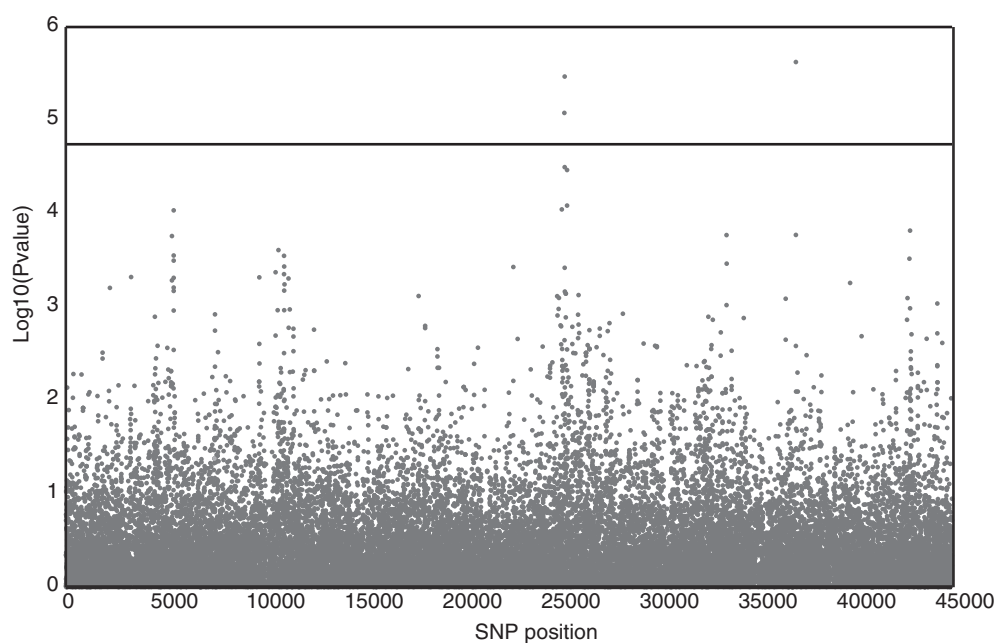

Fig. 2 GWAS results for early vigor in the Flint panel. The graph represents - $\log _{10}(P$-values) of the 35963 SNPs tested. The line shows the significant threshold of - $\log _{10}(P$-values $)$

PUT-163a-78121249-4393 on chr3 for days to emergence with an intracellular signal transduction function and there were eight possible candidate genes in the interval (Table 3). However, as in the QTLs, candidate genes were also looked for in a wider region of $1400 \mathrm{~kb}$ significant around the SNP (Additional file 3: Table S3). The closest candidate gene among the five genes close to the QTL in dent for SPAD on chr1 (associated to PZE-101159230) has a protein heterodimerization activity. For the QTL in dent for SPAD on chr4 (associated to SYN2344), there were four candidate genes and the closest one has a starch synthase activity; Strigens et al. [11] also found a QTL close to this position for one of the environments where they evaluated a panel of maize

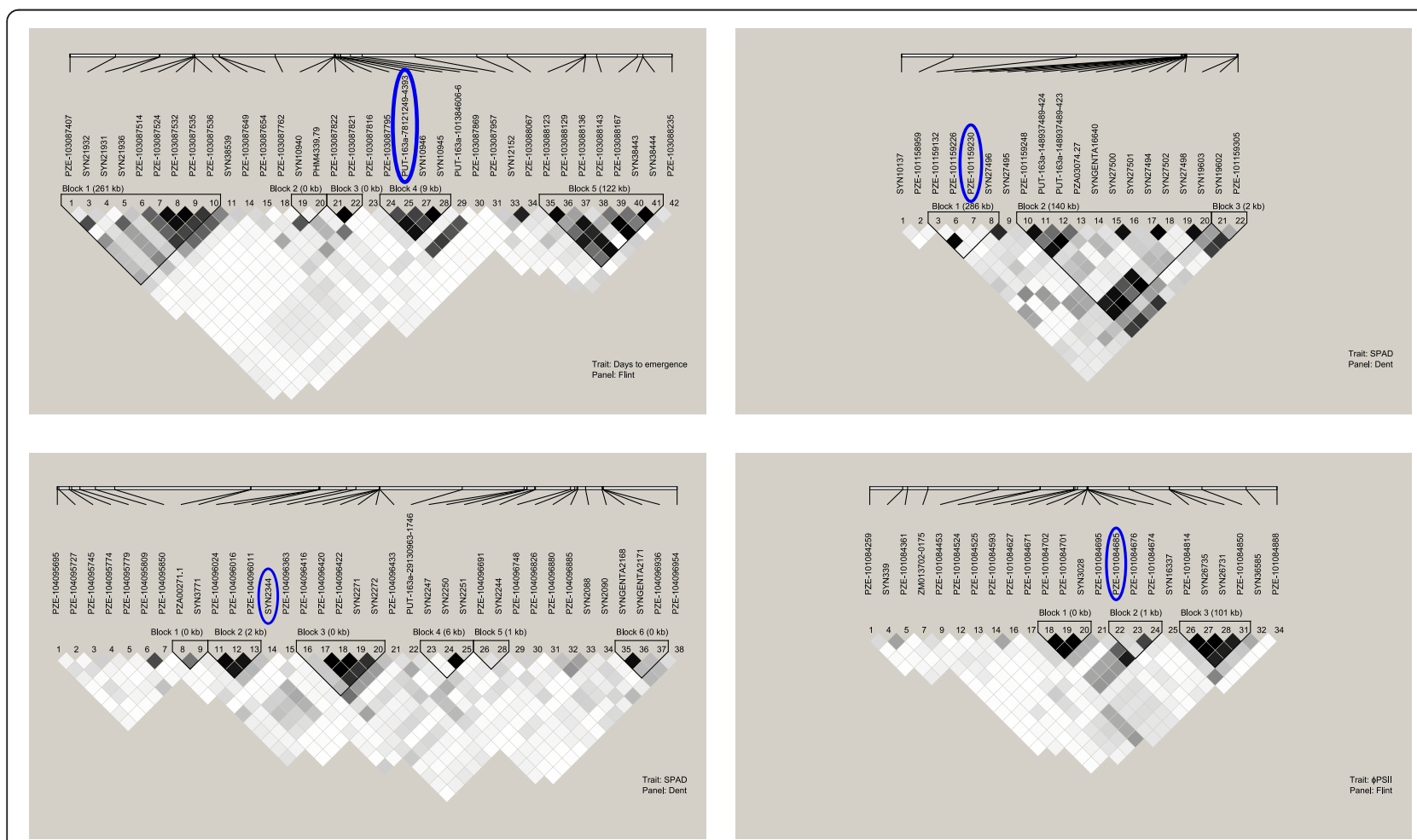

Fig. 3 Local LD, measured as $r^{r}$ values between pairs of SNPs (white, $r^{2}=0$; shades of gray $=0<r^{2}<, 1$; black $r^{2}=1$ ), and haplotype blocks for a 1.4 -kb genomic region that surrounds significant SNPs associated to cold tolerance traits in two association panels of maize inbred lines evaluated under control and cold conditions 
Table 2 Haplotype effects significantly associated to early growth-related traits, from association analyses in two panels of maize

\begin{tabular}{|c|c|c|c|c|c|c|}
\hline \multirow[t]{2}{*}{ SNP } & \multirow[t]{2}{*}{ Trait } & \multirow[t]{2}{*}{ Panel } & \multirow[t]{2}{*}{ Haplotype } & \multirow{2}{*}{$\begin{array}{l}\text { Haplotype } \\
\text { Frecuency }\end{array}$} & \multirow{2}{*}{$\begin{array}{l}\text { Haplotipe } \\
\text { Mean }\end{array}$} & \multirow{2}{*}{$\begin{array}{l}\text { Additive effects } \\
\text { Average }\end{array}$} \\
\hline & & & & & & \\
\hline \multirow[t]{2}{*}{ PUT-163a-78121249-4393 } & Days to emergence & Flint & $\mathrm{G}, \mathrm{C}, \mathrm{C}, \mathrm{A}$ & 15 & $11.80 \pm 0.23$ & 1.28 \\
\hline & & & $\underline{\mathrm{T}, \mathrm{T}, \mathrm{A}, \mathrm{G}}$ & 80 & $11.66 \pm 0.09$ & 0.16 \\
\hline \multirow[t]{4}{*}{ PZE-101159230 } & Chlorophyll content (SPAD) & Dent & $\mathrm{G}, \underline{T}, \mathrm{C}, \underline{C}$ & 51 & $4.54 \pm 0.17$ & -1.26 \\
\hline & & & $\underline{A, T, T, C}$ & 20 & $5.06 \pm 0.27$ & -0.90 \\
\hline & & & $\mathrm{G}, \mathrm{T}, \mathrm{C}, \mathrm{T}$ & 18 & $4.25 \pm 0.24$ & -1.38 \\
\hline & & & $G, C, C, C$ & 11 & $4.06 \pm 0.36$ & -1.98 \\
\hline \multirow[t]{2}{*}{ SYN2344 } & Chlorophyll content (SPAD) & Dent & $\underline{G}$ & 44 & $4.76 \pm 0.17$ & -3.04 \\
\hline & & & $A$ & 54 & $4.19 \pm 0.14$ & -3.42 \\
\hline \multirow[t]{3}{*}{ PZE-101084685 } & DPSII & Flint & $\underline{C C A}$ & 46 & $442 \pm 10$ & 238 \\
\hline & & & $\underline{\mathrm{CTG}}$ & 33 & $450 \pm 13$ & 228 \\
\hline & & & ATG & 13 & $322 \pm 29$ & 189 \\
\hline \multirow[t]{3}{*}{ SYN24026 } & DPSII & Flint & $\mathrm{C}, \underline{\mathrm{A}, \mathrm{G}}, \mathrm{G}$ & 49 & $465 \pm 10$ & 55 \\
\hline & & & $\mathrm{C}, \mathrm{A}, \mathrm{G}, \mathrm{A}$ & 27 & $418 \pm 12$ & 59 \\
\hline & & & $\mathrm{C}, \mathrm{G}, \mathrm{T}, \mathrm{G}$ & 15 & $333 \pm 21$ & -2 \\
\hline \multirow[t]{3}{*}{ PZE-101106625 } & Early vigor & Dent & $\mathrm{T}, \underline{C, G, G, G, C, C, A}$ & 39 & $3.99 \pm 0.07$ & 1.10 \\
\hline & & & $\underline{C}, \underline{C}, T, A, A, T, C, G$ & 16 & $4.04 \pm 0.10$ & 1.02 \\
\hline & & & 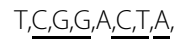 & 22 & $4.03 \pm 0.47$ & 1.10 \\
\hline \multirow[t]{2}{*}{ PZE-105041198 } & Early vigor & Flint & $\underline{T}$ & 73 & $3.95 \pm 0.04$ & -1.19 \\
\hline & & & C & 26 & $3.53 \pm 0.07$ & -1.61 \\
\hline \multirow[t]{2}{*}{ PZE-105041551 } & Early vigor & Flint & C & 51 & $3.61 \pm 0.05$ & 0 \\
\hline & & & $\underline{T}$ & 38 & $4.07 \pm 0.05$ & 0.42 \\
\hline \multirow[t]{2}{*}{ PZE-107098206 } & Early vigor & Flint & $\mathrm{CT}$ & 51 & $3.62 \pm 0.05$ & -0.19 \\
\hline & & & IT & 42 & $4.03 \pm 0.05$ & 0.02 \\
\hline
\end{tabular}

The most favorable allele for each SNPs is underlined. haplotypes are considered when the frequency is greater than $10 \%$

inbred lines for cold tolerance. The closest candidate gene between the two genes close to the QTL in flint for ФPSII on chr1 (PZE-101084685) has an oxidoreductase activity. There were three candidate genes around a QTL in dent for early vigor on chr1 (PZE-101106625) and the closest one has an unknown activity. The only candidate gene in the QTL interval in flint for early vigor on chr5 (PZE-105041551) has a sequence regulator activity. A second QTL in flint for early vigor on chr5 is only around $600 \mathrm{~kb}$ apart (PZE-105041198) and the closest candidate gene among the two in this QTL interval has a protein kinase activity. Finally, the QTL in flint for early vigor located on chro7 (PZE-107098206) had nine candidate genes in the interval and the closest one has an unknown activity; but near this location, Strigens et al. [11] found a QTL for ФPSII, a trait related to early vigor, that was associated to a subtilisin-like protease precursor and a putative ethylene-insensitive3-like protein. Several of the candidate genes identified have unknown function in maize and for many others, the annotation is based on homology to other species. These candidate genes could be studied in subsequent research projects in order to understand their role in the genetic regulation of cold tolerance.

\section{Breeding strategies for improving cold tolerance}

There are few significant QTL associated with cold tolerance, which explain a small proportion of the phenotypic variance for cold tolerance characters. Therefore, it would be interesting to build synthetics of lines with favorable alleles of significant QTL for cold tolerance. These synthetics could be the base material to start phenotypic or genomic selection programs aiming at the development of lines with improved cold tolerance. To choose the lines, we should take into account significant SNPs and if they are linked to other SNPs forming haplotype groups. There are 47 flint inbreds with favorable alleles for all six QTL associated with cold tolerance. However, there are not inbreds with all favorable alleles for all SNPs of haplotypes groups. It is because the combination of favorable alleles for the SNP SYN24026 group, associated to ФPSII, was shown only by $\mathrm{CH} 19-1$, UHF07721H and UHL016. These inbreds did not have favorable alleles for other traits but they should be part 
Table 3 Candidate genes from the association analyses for cold tolerance traits in two association panels of maize

\begin{tabular}{|c|c|c|c|c|c|}
\hline Chr. & $\begin{array}{l}\text { SNP ID and position of } \\
\text { significant SNP (bp) }\end{array}$ & Gene ID & Start (bp) & Stop (bp) & Function/Subcellular localization \\
\hline \multicolumn{6}{|c|}{ Days to emergence } \\
\hline \multirow[t]{9}{*}{3} & \multirow{9}{*}{$\begin{array}{l}\text { PUT-163a-78121249-4393 } \\
145737736\end{array}$} & GRMZM2G061206 & 145636198 & 145639549 & Antiporter \\
\hline & & GRMZM2G061127 & 145642310 & 145643935 & Proteolysis/Chloroplast stroma localization \\
\hline & & GRMZM2G174274 & 145762729 & 145764119 & Signal transduction/Intracellular \\
\hline & & GRMZM2G174249 & 145763792 & 145766257 & Carbohydrate, response to wounding/Cell wall vacuole \\
\hline & & GRMZM2G174221 & 145771397 & 145774255 & Vacuole \\
\hline & & GRMZM2G174196 & 145774369 & 145777597 & Protein binding \\
\hline & & GRMZM2G174137 & 145786387 & 145795884 & Catalytic activity \\
\hline & & GRMZM2G074241 & 145796992 & 145799980 & ATPase activity/Membrane \\
\hline & & GRMZM2G375807 & 145817237 & 145825052 & ATPase activity/Membrane \\
\hline \multicolumn{6}{|c|}{ Chlorophyll content (SPAD) } \\
\hline \multirow[t]{5}{*}{1} & \multirow{5}{*}{$\begin{array}{l}\text { PZE-101159230 } \\
201477347\end{array}$} & GRMZM2G419024 & 201439240 & 201443106 & Triosephosphate isomerase activity \\
\hline & & GRMZM5G899800 & 201502394 & 201505169 & Protein heterodimerization activity \\
\hline & & GRMZM2G416069 & 201513870 & 201519179 & Protein heterodimerization activity/Cohesin complex \\
\hline & & GRMZM2G115730 & 201519254 & 201520692 & Unknown \\
\hline & & GRMZM2G115750 & 201522268 & 201525873 & Receptor/Membrane, ER, Golgi \\
\hline \multirow[t]{4}{*}{4} & \multirow{4}{*}{$\begin{array}{l}\text { SYN2344 } \\
172689894\end{array}$} & GRMZM2G130043 & 172635729 & 172706662 & Starch synthase \\
\hline & & GRMZM2G130002 & 172714527 & 172719310 & Protein binding/Plasma membrane \\
\hline & & GRMZM2G129979 & 172721820 & 172724795 & G10 protein/Nucleous \\
\hline & & GRMZM2G178398 & 172777639 & 172783737 & Epsin like protein \\
\hline \multicolumn{6}{|c|}{ ФPSII ${ }^{\mathrm{a}}$} \\
\hline \multirow[t]{2}{*}{1} & \multirow{2}{*}{$\begin{array}{l}\text { PZE-101084685 } \\
73380804\end{array}$} & GRMZM2G172244 & 73387395 & 73390846 & Unknown \\
\hline & & GRMZM2G171420 & 20758772 & 20762634 & Unknown \\
\hline \multirow[t]{2}{*}{4} & \multirow{2}{*}{$\begin{array}{l}\text { SYN24026 } \\
20738948\end{array}$} & GRMZM2G171394 & 20762995 & 20764457 & Rapid alkalinization factor \\
\hline & & GRMZM2G078143 & 20795669 & 20799891 & Glycine hydroxymethyltransferase/Plasma membrane \\
\hline \multicolumn{6}{|c|}{ Early vigor ${ }^{b}$} \\
\hline \multirow[t]{3}{*}{1} & \multirow{3}{*}{$\begin{array}{l}\text { PZE-101106625 } \\
110914351\end{array}$} & GRMZM2G084825 & 110955450 & 110958921 & Protein serine threonine kinase activity \\
\hline & & GRMZM2G154216 & 110981685 & 110983586 & Transferase activity of acyl groups (no amino-acyl) \\
\hline & & GRMZM2G341036 & 27150769 & 27152027 & Unknown \\
\hline \multirow[t]{2}{*}{5} & \multirow{2}{*}{$\begin{array}{l}\text { PZE-105041198 } \\
27247368\end{array}$} & GRMZM2G102862 & 27218204 & 27224147 & Protein kinase activity \\
\hline & & GRMZM2G405090 & 27787706 & 27788723 & Putative uncharacterized protein \\
\hline 5 & $\begin{array}{l}\text { PZE-105041551 } \\
27857856\end{array}$ & GRMZM2G127510 & 153320097 & 153324724 & Nucleotide binding \\
\hline \multirow[t]{8}{*}{7} & \multirow{8}{*}{$\begin{array}{l}\text { PZE-107098206 } \\
153421340\end{array}$} & GRMZM2G127499 & 153326363 & 153329791 & Unknown \\
\hline & & GRMZM2G429396 & 153330870 & 153331777 & Response to high light intensity/Cytoplasm \\
\hline & & GRMZM2G124794 & 153413756 & 153414250 & Deoxyribodipyrimidine photo-lyase activity \\
\hline & & GRMZM2G423478 & 153416453 & 143416869 & Unknown \\
\hline & & GRMZM2G180027 & 153457846 & 153464555 & Unknown \\
\hline & & GRMZM2G480480 & 153464547 & 153475981 & Protein binding \\
\hline & & GRMZM2G180080 & 153485164 & 153487062 & Nucleotide binding \\
\hline & & GRMZM2G180082 & 153490387 & 153492351 & $\begin{array}{l}\text { Oxidoreductase activity, acting on paired donors, } \\
\text { with incorporation or reduction of molecular oxygen }\end{array}$ \\
\hline
\end{tabular}


of the synthetic to keep favorable alleles for cold tolerance. The best inbreds were EZ33 and Ia2132 with 14 favorable alleles out of the 15 significant SNPs and haplotype groups (Additional file 4: Table S4). On the other hand, among the 47 inbreds six belonged to the group Northern Flint, 27 to the Northern Flint family of D171, and one to the Northern Flint family of FV7. The remaining 13 selected inbreds belonged to NoNorthern Flint groups according to the grouping revealed in our previous study [4]. Among the 47 selected inbreds, four (D171, EZ33, Ia2132 and UH1494) had also the favorable alleles for the three SNPs most significantly associated in the testcross trials under cold conditions (Additional file 4: Table S4). These four inbreds are unrelated and could be the base of a Northern Flint synthetic with the best combination of cold tolerance alleles and a wide genetic base, considering the diversity available within the Northern Flint race. CH19-1, UHF07721H and UHL016 are also Northern Flint and should be included in the synthetic to increase ФPSII under cold conditions.

Concerning the dent panel, four of the inbreds (EZ47, F924, NK807 and PHJ40) carried the favorable alleles for the three QTL detected for inbred lines per se evaluated under cold conditions (Additional file 5: Table S5) and all of them had favorable alleles for all SNPs of haplotype group for SPAD and 6/8 for haplotype group for early vigor. These inbreds were unrelated and belonged to a mixed group, except F924 that belongs to the Stiff Stalk pool. Besides these four inbreds, there were eight inbred lines (B37, EZ11A, EZ46, F618, F918, FV317, N6, and PHG80) that had two favorable alleles for the QTL of inbreds per se and for two QTL for the testcrosses. Most of the inbreds carrying two favorable alleles belong to the "mixed" group. Especially interesting were EZ11A and EZ46 because they had one favorable allele for early vigor that was not present in previously selected lines. However, to complete the favorable haplotype for early vigor we need the favorable allele for the first SNP of the group. AS5707, B103, F904 or PHK29 could be donor of this allele, besides they had two favorable alleles for the QTL of inbreds per se.

Among the inbreds previously selected for cold tolerance per se [4], in the present work the flint inbreds FV71 and UH006, and the dent inbreds LH85 and FV335 were included in the set of selected inbreds based on genotype (Additional file 4: Table S4 and Additional file 5: Table S5). Considering the groups, the northern flint group D171 and the Iodent group PH207 were among the selected groups based on both phenotype and genotype.

\section{Conclusions}

From this study, we draw four conclusions. (1) The use of two large panels of inbreds from the dent and flint genepools enabled identifying the largest number of QTL for cold tolerance ever published. (2) More QTL for cold tolerance were found in the European flint panel than in the dent panel. (3) Most of the QTL were associated with days to emergence and efficiency of photosystem II. (4) These results open new possibilities for improving cold tolerance either with genome-wide selection or with marker-assisted selection in maize breeding.

\section{Additional files}

Additional file 1: Table S1. Summary of the compression mixed linear model analysis for cold tolerance traits in two panels of dent and flint maize inbred lines evaluated in a cold chamber under cold and control conditions per se and as testcrosses, and number of SNPs declared as significantly associated to each trait. (DOC $372 \mathrm{~kb}$ )

Additional file 2: Table S2. SNPs declared as significantly associated to cold tolerance-related traits, chromosome location, P-Value, allele effect estimates, proportion of total variance explained by the SNPs from the association analyses for cold tolerance traits in two association panels of maize inbred lines evaluated in test-crosses under cold and control conditions and per se under control conditions. (DOCX $47 \mathrm{~kb}$ )

Additional file 3: Table S3. Candidate genes from the association analyses for cold tolerance traits in two association panels of maize. Genes in a $1400 \mathrm{~kb}$ interval surrounding the significant SNPs are listed with their identifier. The gene closest to the significant SNP is indicated in bold. (DOCX $34 \mathrm{~kb}$ )

Additional file 4: Table S4. Flint inbred lines with the favorable allele for the SNPs significantly associated to cold tolerance-related traits and allele composition for the significant SNPs with highest level of signification from the testcross trials of flint inbreds. (DOCX $36 \mathrm{~kb}$ )

Additional file 5: Table S5. Dent inbred lines with the allele composition for the SNPS significantly associated to cold tolerancerelated traits and allele composition for the significant SNPs with highest level of signification from the testcross trials of flint inbreds. Data: Best linear unbiased estimates (BLUEs) of early growth-related traits used for association analyses for cold tolerance traits in two association panels of maize inbred lines evaluated per se and hybrids under control and cold conditions. (DOCX $30 \mathrm{~kb}$ )

\section{Abbreviations}

SSR, simple sequence repeats; GWAS, genome-wide association analyses; SNP, single nucleotide polymorphism; QTL, quantitative trait loci; BLUE, Best linear unbiased estimators; MLM, mixed linear model

\section{Acknowledgements}

This research was supported in the framework of the Plant-KBBE program (project acronym "Cornfed") by the Spanish Ministry of Science and Innovation (proj. EUI2008-03642 and EUI2008-03635), the Spanish Plan for Research and Development (AGL2013-48852-C3-1-R), the French National Agency for Research (ANR, Ministry of High Education and Research), and the German Federal Ministry of Education and Research (grant number 0315461A-D).

\section{Availability of data and materials}

Phenotypic data are available in a supplementary file, and materials are available from the authors upon request.

\section{Authors' contributions}

$P R$, VMR and RM carried out the experiments in the growth chamber, made the final analyses and wrote the manuscript, assisted by $A O ; R R$ and $A C$ obtained and analyzed the molecular data; CG, AE, CCS, EB, TA, DB, JMG, LC, $M O, A A, J R G$, and $J L$ provided genetic materials and reviewed the manuscript. All authors cooperated in the design of the project and the article, and approved the final manuscript. 


\section{Competing interests}

The authors declare that they have no competing interests.

\section{Consent to publish}

Not applicable.

\section{Ethics approval and consent to participate}

Not applicable.

\section{Author details}

${ }^{1}$ Misión Biológica de Galicia, Spanish National Research Council (CSIC), PO Box 2836080, Pontevedra, Spain. ${ }^{2}$ INRA, UMR de Génétique Végétale/ Université Paris-Sud - CNRS - AgroParisTech, Gif-sur-Yvette, France. ${ }^{3}$ UMR INRA/USTL 1281 Stress Abiotiques et Différenciation des Végetaux cultivés, Péronne, France. ${ }^{4}$ Institute of Plant Breeding, Seed Science and Population Genetics, Universität Hohenheim, Stuttgart, Germany. ${ }^{5}$ Plant Breeding, Technische Universität München, Freising, Germany. ${ }^{6}$ Molecular Genetics, Leibniz Institute of Plant Genetics and Crop Plant Research (IPK), Gatersleben, Germany. ${ }^{7}$ INRA-VERSAILLES, Evry, France. ${ }^{8}$ Centro Investigacións Agrarias Mabegondo (CIAM), A Coruña, Spain. ${ }^{9}$ KWS SAAT AG, Einbeck, Germany.

${ }^{10}$ Estación Experimental de Aula Dei (CSIC), Saragossa, Spain.

${ }^{11} N E$ IKER-Instituto Vasco de Investigación y Desarrollo Agrario, Vitoria, Spain

${ }^{12}$ INRA, Stn Expt Mais, F-40590 St Martin De Hinx, France.

Received: 8 December 2015 Accepted: 20 May 2016

Published online: 06 June 2016

\section{References}

1. Strigens A, Grieder C, Haussmann BIG, Melchinger AE. Genetic variation among inbred lines and testcrosses of maize for early growth parameters and their relationship to final dry matter yield. Crop Sci. 2012;52:1084-92.

2. Kucharik CJ. A multidecadal trend of earlier corn planting in the central USA. Agron J. 2006;98:1544-50.

3. Revilla P, Butrón A, Cartea ME, Malvar RA, Ordás A. Breeding for cold tolerance. In: Ashraf M, Harris PJC, editors. Abiotic Stresses. Plant resistance through breeding and molecular approaches. New York: The Haworth Press, Inc; 2005. p. 301-98.

4. Revilla P, Rodríguez VM, Ordás A, Rincent R, Charcosset A, Giauffret C, et al. Cold tolerance in two large maize inbred panels adapted to European climates. Crop Sci. 2014;54:1981-91.

5. Rodríguez VM, Butrón A, Rady MOA, Soengas P, Revilla P. Identification of QTLs involved in the response to cold stress in maize (Zea mays L.). Mol Breed. 2014:33:363-71.

6. Rodríguez VM, Romay MC, Ordás A, Revilla P. Evaluation of the European maize (Zea mays L.) germplasm under cold conditions. Gen Res Crop Evol. 2010;57:329-35.

7. Leipner J, Jompuk C, Camp K, Stamp P, Fracheboud Y. QTL studies reveal little relevance of chilling-related seedling traits for yield in maize. Theor Appl Genet. 2008;116:555-62.

8. Jompuk C, Fracheboud Y, Stamp P, Leipner J. Mapping of quantitative trait loci associated with chilling tolerance in maize (Zea mays L.) seedlings grown under field conditions. J Exp Bot. 2005;56:1153-63.

9. Presterl T, Ouzunova M, Schmidt W, Moeller EM, Roeber FK, Knaak C, et al. Quantitative trait loci for early plant vigour of maize grown in chilly environments. Theor Appl Genet. 2007;114:1059-70.

10. Rodríguez VM, Butrón A, Malvar RA, Ordás A, Revilla P. QTLs for cold tolerance in the maize IBM population. Int J Plant Sci. 2008;169:551-6.

11. Strigens A, Freitag NM, Gilbert X, Grieder C, Riedelsheimer C, Schrag TA, et al. Association mapping for chilling tolerance in elite flint and dent maize inbred lines evaluated in growth chamber and field experiments. Plant Cell Env. 2013; 36:1871-87.

12. Frascaroli $E$, Landi P. Divergent selection in a maize population for germination at low temperature in controlled environment: study of the direct response, of the trait inheritance and of correlated responses in the field. Theor Appl Genet. 2013;126:733-46.

13. Lee EA, Staebler MA, Tollenaar M. Genetic variation in physiological discriminators for cold tolerant-early autotrophic phase of maize development. Crop Sci. 2002;42:1919-29.

14. Mosely PR, Crosbie TM, Mock JJ. Mass selection for improved cold and density tolerance of two maize populations. Euphytica. 1984;33:263-9.
15. Revilla P, Malvar RA, Cartea ME, Butrón A, Ordás A. Inheritance of cold tolerance at emergence and during early season growth in maize. Crop Sci. 2000;40:1579-85.

16. Semuguruka $\mathrm{GH}$, Compton WA, Sullivan $\mathrm{CY}$, Thomas MA. Some measures of temperature response in corn (Zea mays L.). Maydica. 1981;26:209-18.

17. Verheul MJ, Picatto C, Stamp P. Growth and development of maize (Zea mays L.) seedlings under chilling conditions in the field. Eur J Agron. 1996:5:31-43.

18. Rincent $R$, Laloë $D$, Nicolas $S$, Altmann T, Brunel D, Revilla P, et al. Maximizing the reliability of genomic selection by optimizing the calibration set of reference individuals: comparison of methods in two diverse groups of maize inbreds (Zea mays L.). Genetics. 2012;192:715-28.

19. Ganal MW, Durstewitz G, Polley A, Bérard A, Buckler ES, Charcosset A, et al. A large maize (Zea mays L.) SNP genotyping array: development and germplasm genotyping, and genetic mapping to compare with the B73 reference genome. PLoS One. 2011;6, e28334.

20. SAS Institute Inc. SAS 9.3 Guide to software updates. Cary, North Carolina; 2011

21. Bradbury PJ, Zhang Z, Kroon DE, Casstevens TM, Ramdoss Y, Buckler ES. TASSEL: software for association mapping of complex traits in diverse samples. Bioinformatics. 2007;23:2633-5.

22. Yu J, Pressoir G, Briggs WH, Vroh I, Yamasaki I, Doebley JF, et al. A unified mixed-model method for association mapping that accounts for multiple levels of relatedness. Nat Genet. 2006:38:203-8.

23. Zhang Z, Ersoz E, Lai CQ, Todhunter RJ, Tiwari HK, Gore MA, et al. Mixed linear model approach adapted for genome-wide association studies. Nat Genet. 2010;42:355-60.

24. Li J, Ji L. Adjusting multiple testing in multilocus analyses using the eigenvalues of a correlation matrix. Heredity. 2005;95:221-7.

25. Sen TZ, Harper LC, Schaeffer ML, Andorf CM, Seigfried TE, Campbell DA, et al. Choosing a genome browser for a model organism database: surveying the maize community. Database 2010: baq007 http://database. oxfordjournals.org/content/2010/baq007.abstract

26. Barrett, J. C., B. Fry, J. Maller, and M. J. Daly, 2005 Haploview: analysis and visualization of LD and haplotype maps. Bioinformatics 21: 263-265. Holland $J B$, Nyquist WE, Cervantes-Martínez CT. Estimated an interpreting heritability for plant breeding: An update. In: Janick J, editor. Plant Breeding Reviews, vol. Volume 22. Hoboken, New Jersey, USA: Jonh Wiley \& Sons; 2003. p. 9-112

27. Gabriel SB, Schaffner SF, Nguyen H, Moore JM, Roy J, et al. The structure of haplotype blocks in the human genome. Science. 2002;296:2225-9.

28. Samayoa LF, Malvar RA, Olukolu BA, Holland JB, Butrón A. Genome-wide association study reveals a set of genes associated with resistance to the Mediterranean corn borer (Sesamia nonagrioides L.) in a maize diversity panel. BMC Plant Biol. 2015;15:35.

29. Sorkheh K, Malysheva-Otto LV, Wirthensohn MG, Tarkesh-Esfahani S, Martínez-Gómez P. Linkage disequilibrium, genetic association mapping and gene localization in crop plants. Gen Mol Biol. 2008;31:805-14.

30. Fournier-Level A, Korte A, Cooper MD, Nordborg M, Schmitt J, Wilczek AM. A map of local adaptation in Arabidopsis thaliana. Science. 2011;334:86-9.

31. Lipka AE, Gore MA, Magallanes-Lundback M, Mesberg A, Lin H, Tiede T, Chen $C$, et al. Genome-wide association study and pathway-level analysis of tocochromanol levels in maize grain. G3 (Bethesda). 2013:3:1287-99.

32. Schnable PS, Ware D, Fulton RS, Stein JC, Wei F, Pasternak S, et al. The B73 maize genome: complexity, diversity, and dynamics. Science. 2009;326:1112-5.

\section{Submit your next manuscript to BioMed Central and we will help you at every step:}

- We accept pre-submission inquiries

- Our selector tool helps you to find the most relevant journal

- We provide round the clock customer support

- Convenient online submission

- Thorough peer review

- Inclusion in PubMed and all major indexing services

- Maximum visibility for your research

Submit your manuscript at www.biomedcentral.com/submit 